\title{
Treating the Small Airways
}

\author{
Omar S. Usmani \\ Airway Disease Section, National Heart and Lung Institute, Imperial College London, and Royal Brompton Hospital, \\ London, UK
}

\section{Key Words}

Inhaled drug delivery • Small particle aerosols • Asthma •

Chronic obstructive pulmonary disease

\begin{abstract}
The final article in this series evaluates the approaches undertaken to treating the small-airway region of the lungs and the clinical implications of inhaled therapy targeting the periphery in patients with asthma and chronic obstructive pulmonary disease.

Copyright $\odot 2012$ S. Karger AG, Basel
\end{abstract}

\section{Introduction}

From the previous articles in this current Thematic Review Series in Respiration, the authors have described that pathological, immunological and structural abnormalities occur in the small airways of patients with asthma and chronic obstructive pulmonary disease (COPD); that these abnormalities contribute to the physiological observations of the small airways being the major site of airflow limitation, and that small airways are involved in the clinical expression of these diseases [1-3]. Involvement of the small airways has been observed not only in patients with severe asthma [4], but also in those with mild disease $[5,6]$ and in patients with nocturnal and exercise-induced asthma [7-9]. There is therefore a rationale to treat the small airways and, importantly, to understand whether treating this airway region impacts on patient symptoms and better control of the disease state.

Certainly, oral and parenterally administered drugs absorbed through the systemic circulation reach the lungs and eventually the small airways, where some studies have shown they can influence markers of small-airway inflammation $[10,11]$. However, there are distinct therapeutic advantages to direct a drug to the lungs via the inhaled route: a smaller drug dose can be used; the onset of action is more rapid, and, particularly for corticosteroids, the incidence of side effects is reduced. Recent advances in formulation science and aerosol technology have improved the efficiency of inhaled drug deposition

Previous articles in this series: 1. Usmani OS: Unravelling the small airways: structure-function-treatment relationships in asthma and COPD. Respiration 2012;84:1-3. 2. Hamid Q: Pathogenesis of small airways in asthma. Respiration 2012;84:4-11. 3. Baraldo S, Turato G, Saetta M: Pathophysiology of the small airways in chronic obstructive pulmonary disease. Respiration 2012;84:89-97. 4. Verbanck S: Physiological measurement of the small airways. Respiration 2012;84:177-188. 5. King GG: Tomographic imaging of small airways. Respiration 2012;84:265-274.

\section{KARGER}

Fax +41613061234

E-Mail karger@karger.ch

www.karger.com
(C) 2012 S. Karger AG, Basel

0025-7931/12/0846-0441\$38.00/0

Accessible online at: www.karger.com/res
Dr. Omar S. Usmani

Airway Disease Section (c/o Asthma Laboratory), NHLI

Imperial College London, Dovehouse Street

London SW3 6LY (UK)

E-Mailo.usmani@imperial.ac.uk 
within the lungs and allowed the delivery of aerosolised medicines into the small airways via the inhaled route. This final article in this series evaluates the approaches undertaken to treating the small-airway region of the lungs and the clinical implications of inhaled therapy targeting the periphery in patients with asthma and COPD.

\section{Inhalation Medicine}

Inhalation therapy has its roots as far back as $2000 \mathrm{BC}$ in Indian ayuverdic medicine, where the leaves of the plant Datura stramonium, which had anticholinergic properties, were made into a paste and smoked from a pipe to help alleviate respiratory symptoms [12]. History shows that all the great ancient civilisations embraced inhaled aerosolised therapy to treat ailments of the chest: the ancient Egyptians inhaled vapours of another anticholinergic, Hyosycamus muticus, placed on hot bricks; Hippocrates advocated the inhalation of sea mists and hot vapours to ease airway obstruction, and, in the Arabian dynasty, the acclaimed physician Ibn Sina (Avicenna) advocated the inhalation of essential oils of pine and eucalyptus, medicaments that are still in use today in proprietary over-the-counter inhalation medicines. During the 1800s, the Industrial Revolution spread throughout the Western hemisphere, and rather extraordinarily it was during this time that cigarettes containing Daturatobbaco mixtures became available to be smoked by patients suffering from asthma [13].

Modern-day inhalation therapy began with the infamous words of a 13-year-old asthmatic girl to her father: 'daddy, why can't they put my asthma medicine in a spray can like they do hair spray?' [14]. Susie's father happened to be George Mason, the president of Riker Laboratories (now $3 \mathrm{M}$ ), and the following day he instructed his chief chemist, Irving Porusch, to address the problem that had been presented to him by his daughter. Within 1 year, in 1956, Riker Laboratories had invented the Medihaler, the world's first pressurised metered-dose inhaler (pMDI). However, over 50 years later, there is confusion in aerosol medicine! In any formulary in any part of the world, there will be more than 250 inhaler device, drug and spacer combinations available to health care practitioners to treat their respiratory patients. To compound matters, studies show most health care workers are uncertain about the correct use of inhalers: in particular physicians themselves show the least knowledge with respect to aerosol therapy $[15,16]$.
The inhaler devices used in current clinical practice include dry-powder inhalers (DPIs), nebulisers and pMDIs with or without valve-holding chambers or spacers. Surprisingly though, most of these devices are quite inefficient where, at best, only $10-20 \%$ of the emitted drug dose actually reaches the lungs [17]. The majority of the wasted dose impacts on the oropharynx giving rise to the potential for local and systemic adverse effects. As consumers, we would probably all be complaining if our washing machine required five times as much powder to efficiently give one wash, or our petrol engines required five times as much fuel for one journey; so why, as a respiratory community, have we been complacent about the inefficiency of aerosolised medicine that forms the cornerstone of our therapeutic armoury in the treatment of diseases of the chest?

\section{Factors Influencing the Deposition of Medical Aerosols in the Lung: Particle Size}

It is well recognised that there are several factors that affect the deposition of medical aerosols in the lung and that, ultimately, these impact upon the efficiency of inhaled drug delivery [18] (table 1). Patient factors are often difficult to control or overcome, and they clearly modify the amount of drug emitted from the inhaler device that eventually reaches the lungs. So should not the scientific direction be to optimise the amount of drug emitted by the inhaler device such that during the device-patient interface, a greater proportion of the drug is available to be deposited in the lungs and lesser amounts are wasted?

Of the aerosol characteristics (table 1), the most important determinant that can improve the efficiency of inhaled drug delivery is particle size. In vitro experimental modelling coupled with mathematical calculations has determined that aerosol particle size influences the total lung and regional airway site of inhaled drug deposition $[19,20]$. Particles $>6 \mu \mathrm{m}$ preferentially deposit in the oropharynx, those between 2 and $6 \mu \mathrm{m}$ target the lungs and those that are $<2 \mu \mathrm{m}$ reach the alveoli or are exhaled [21]. However, these models do not account for features of inhaled drug delivery in vivo that can affect aerosol deposition in the lungs, such as a breath-hold pause after inhalation, or the effect of the diseased lung environment or different inhalation manoeuvres from pMDIs and DPIs (single breath) compared to nebulisers (tidal breathing). Usmani et al. [22] undertook a hypothesis-driven study to explore the effect of different drug particle sizes and inhalation flows on aerosol lung depo- 
sition in vivo in patients with asthma. The authors radiolabelled monodisperse therapeutic aerosols of salbutamol at particle sizes of 1.5, 3 and $6 \mu \mathrm{m}$ and undertook twodimensional $\gamma$-scintigraphic imaging to assess drug distribution in the total lung and regional airways. They observed the smaller $1.5-\mu \mathrm{m}$ aerosols achieved better total lung and greater peripheral-airway deposition than the larger particles (table 2). It was also noted that the smaller aerosols deposited far less in the oropharynx compared to the larger particles, and, interestingly, the smaller 1.5$\mu \mathrm{m}$ aerosols were exhaled far less than was previously predicted by in vitro models. The authors also found that the smaller aerosols were less affected by rapid changes in inhalation flow and that, overall, slower inhalation flows achieved better lung deposition. These findings have supported the formulation chemistry and aerosol technology developments the pharmaceutical industry and device companies have taken over the last decade with respect to the new generation of inhaler devices for more efficient drug delivery to the lungs.

\section{Particle Size and Formulation Chemistry}

The Montreal protocol was the wake-up call to the industry and a driver to respiratory medicine marking a key milestone in inhaled aerosol delivery in modern times since the introduction of the pMDI $[14,23]$. This critical turning point in the phasing out of ozone-depleting chlorofluorocarbons (CFCs) from pMDIs propelled the industry and device companies to accelerate the development of alternative formulations, different propellants and newer inhaler devices. The hydrofluoroalkanes (HFA) became promising alternative propellant compounds (HFA-134a and HFA-227) with physicochemical properties similar to the CFCs used in pMDIs, and these propellants allowed the transition of most of the CFC-pMDI devices to the present-day nonCFC pMDIs [24]. Through this advancement in formulation science, it became recognised that the particle size of aerosolised drugs was very much dependent upon the chemical characteristics of the formulation; in particular, the reformulation of existing corticosteroid compounds into HFA propellants resulted in two distinct classes of aerosols: HFA suspensions and HFA solutions. HFA suspension formulations tended to retain the same particle size as the CFC formulations [25]; however it was noted that HFA-solution-based pMDI aerosols had much smaller particle sizes than HFA suspension pMDIs or, indeed, dry-powder formulations in DPIs
Table 1. Factors influencing the deposition of medical aerosols in the lung

\begin{tabular}{lcc}
\hline Aerosol characteristics & & Patient factors \\
\cline { 1 - 1 } $\begin{array}{c}\text { Drug particle } \\
\text { Size }\end{array}$ & & Inhalation manoeuvre \\
Density & Inspiratory flow \\
Charge & Inhaled volume \\
Formulation & Breath-hold pause \\
Lipohilicity & Airway \\
Hygroscopicity & Disease \\
Plume & Severity \\
Speed & Device \\
Duration & Acceptance \\
& Compliance \\
\hline
\end{tabular}

Table 2. Monodisperse salbutamol aerosol deposition in asthmatic subjects

\begin{tabular}{lccc}
\hline Deposition & \multicolumn{3}{l}{ Aerosol particle size } \\
\cline { 2 - 4 } & $1.5 \mu \mathrm{m}$ & $3 \mu \mathrm{m}$ & $6 \mu \mathrm{m}$ \\
\hline Total lung deposition, \% & 56 & 50 & 46 \\
Oropharyngeal deposition, \% & 15 & 31 & 43 \\
Exhaled fraction, \% & 22 & 8 & 2 \\
Penetration index & 0.79 & 0.60 & 0.36 \\
\hline
\end{tabular}

Table 3. ICS particle size depends upon the formulation

\begin{tabular}{lll}
\hline Drug & Formulation/device & $\begin{array}{l}\text { MMAD } \\
\mu \mathrm{m}\end{array}$ \\
\hline FP [27] & dry powder/DPI & 5.4 \\
BUD [27] & dry powder/DPI & 4.0 \\
Mometasone furoate [28] & dry powder/DPI & 3.7 \\
FP [29] & HFA suspension/pMDI & 2.4 \\
BDP/formoterol [30] & HFA solution/pMDI & 1.5 \\
BDP [31] & HFA solution/pMDI & 1.1 \\
CIC [32] & HFA solution/pMDI & 1.1 \\
\hline
\end{tabular}

MMAD = Mass median aerodynamic diameter.

[26-32] (table 3). The HFA solution pMDI formulations currently available are the long-acting $\beta_{2}$-agonist formoterol; the corticosteroids ciclesonide (CIC), beclomethasone dipropionate (BDP) and flunisolide, and the drug combination of $\mathrm{BDP} /$ formoterol in a single inhaler. 


\section{Small-Particle Aerosols}

\section{In vitro Analysis}

In an in vitro analysis study, the performance of four inhaled corticosteroid (ICS) HFA-pMDIs of different particle size (median volume diameter) were compared: budesonide (BUD, $3.5 \mu \mathrm{m}$ ), fluticasone propionate (FP, $2.8 \mu \mathrm{m}), \mathrm{BDP}(1.9 \mu \mathrm{m})$ and CIC $(1.9 \mu \mathrm{m})$ [33]. The authors observed the HFA solution aerosols of CIC and BDP had a greater proportion of their drug dose as 'finer particles' (defined as particles $<3.1 \mu \mathrm{m}$ ) than the HFA suspension aerosols of BUD and FP. Indeed, CIC had the largest proportion of its drug mass in the 'fine-particle fraction' (defined as particles $<5 \mu \mathrm{m}$ ). In addition, differences in inspiratory flow (range studied: $10-301 / \mathrm{min}$ ) and air humidity had no significant influence on the particle size distribution for either aerosol. In an in vitro study incorporating the Andersen cascade impactor, the aerodynamic characteristics of the HFA solution pMDI drug combination of $\mathrm{BDP} /$ formoterol was investigated [34]. Both drugs had an $\sim 40 \%$ fine-particle dose (defined as particles $<4.7 \mu \mathrm{m}$ ) and both drugs exhibited a similar particle size distribution at each stage of the cascade impactor. These technological advances in achieving a smaller aerosol particle size and a greater fraction of the drug mass as finer particles have, consequently, been utilised to investigate drug delivery to the pulmonary tree.

\section{Lung and Oropharyngeal Deposition}

In previous studies, the size of the ICS particle strongly affected the aerodynamic properties of the drug and its delivery to the pulmonary tree, in particular, to the distal airways. In a two-dimensional $\gamma$-scintigraphy study in healthy volunteers $(\mathrm{n}=6), 55-60 \%$ of an HFA solution $\mathrm{BDP}$ aerosol (1.1 $\mu \mathrm{m}$, ex-actuator dose) was deposited in the lungs in contrast to only $4-7 \%$ with a CFC-BDP aerosol of larger-particle size $(3.5 \mu \mathrm{m})$ [31]. Interestingly, oropharyngeal deposition was markedly reduced with the small-particle aerosols such that $\sim 30 \%$ of the HFA solution BDP aerosol deposited in the oropharynx, whereas this was $90-94 \%$ with the CFC-BDP aerosol. It was also noted that the HFA-BDP aerosol distribution in the lung images was seen throughout the airways, whereas the larger-particle size CFC-BDP aerosol predominantly deposited in the proximal airways. Similar results were observed in another study involving healthy subjects $(\mathrm{n}=9)$ where the airway deposition of HFA-BDP $(0.9 \mu \mathrm{m})$, CFCFP $(2.0 \mu \mathrm{m})$ and CFC-BDP $(3.5 \mu \mathrm{m})$ were examined [35]. The smaller-particle aerosols achieved greater lung depo- sition ( $53 \%$ ex-actuator dose vs. $\sim 13$ vs. $4 \%$ ) and lower oropharyngeal deposition ( 29 vs. $\sim 78$ vs. $82 \%$ ) for HFABDP, CFC-FP and CFC-BDP, respectively. In a separate study, the total lung deposition of the HFA solution smallparticle corticosteroid aerosol CIC $(1.1 \mu \mathrm{m})$ was studied in healthy volunteers $(n=6)$ using both two- and threedimensional $\gamma$-scintigraphic techniques [32]. HFA-CIC achieved a high lung deposition at 52\% (ex-actuator dose) and a low oropharyngeal deposition of $38 \%$, and, in addition, HFA-CIC was found to be distributed throughout the lung regions. Aerosol deposition patterns in healthy subjects may not always translate into drug distribution within the diseased lungs, and it is important to ascertain the behaviour of aerosolised medication within the airways of the patients themselves.

In the above study involving healthy subjects with HFA solution BDP aerosol [31], the authors also investigated deposition effects in patients with asthma $(\mathrm{n}=16)$ : $56 \%$ of the HFA aerosol was deposited in the lungs and $33 \%$ in the oropharynx. In a recent two-dimensional $\gamma$ scintigraphy lung deposition study in asthmatic patients, the deposition effects of the HFA suspension drug combination aerosol of $\mathrm{FP} / \mathrm{salmeterol}(2.7 \mu \mathrm{m})$ was compared to the HFA solution corticosteroid aerosol of BDP $(0.7$ $\mu \mathrm{m})$ [36]. Consistent with other studies investigating small-particle aerosol deposition, the authors observed smaller aerosol particles achieved greater total lung deposition (58 vs. 16\%) and lower oropharyngeal deposition (35 vs. $77 \%$ ) compared to larger-particle aerosols. The small-particle corticosteroid aerosol of HFA-CIC (1.1 $\mu \mathrm{m})$ has also been studied in mild asthmatics $(\mathrm{n}=12)$ using two-dimensional $\gamma$-scintigraphy, and high lung deposition (52\%) and low oropharyngeal deposition ( $33 \%)$ was reported [37].

An often overlooked characteristic is the ability to achieve lower oropharyngeal deposition by using smaller-particle aerosols, as has been described above, which not only decreases the potential for local side effects and systemic absorption from the swallowed dose, but in parallel improves the amount of drug able to reach the lungs as a result of bypassing the barrier of the oropharyngeal structures. Another important consideration is the exhaled dose from these aerosols. In vitro modelling data have often suggested that a large proportion of inhaled small aerosolised particles eventually become exhaled, suggesting as much as $80 \%$ of the aerosol [20]. However, in silico and in vivo patient data show this not to be the case $[22,38]$ where $\sim 20 \%$ of a monodisperse salbutamol aerosol of $1.5 \mu \mathrm{m}$ delivered to asthmatics was exhaled (table 2). Using HFA solution clinical aerosols of small 
particles in both healthy subjects and asthmatics, it can also be noted from an assessment of the studies presented above that the exhaled fraction ranged between $<4$ and $24 \%$ [31, 32, 35-37].

Another important observation with small-particle aerosols has been the finding of consistent lung deposition in differing disease severities. De Backer et al. [39] assessed the aerodynamic behaviour of the small-particle HFA solution drug combination aerosol of $\mathrm{BDP} /$ formoterol $(1.37 \mu \mathrm{m})$ in the airways of healthy subjects $(\mathrm{n}=$ 8 , forced expiratory volume in $1 \mathrm{~s}, \mathrm{FEV}_{1}, 112 \%$ of predicted), asthmatic patients $\left(\mathrm{n}=8, \mathrm{FEV}_{1} 75 \%\right.$ of predicted $)$ and patients with COPD ( $\mathrm{n}=8, \mathrm{FEV}_{1} 44 \%$ of predicted). The authors observed high total lung deposition (34\%) in healthy subjects, but also, total lung deposition was similar between the different patient populations who had markedly varying airway disease severity: asthmatics (31\%) and COPD patients (33\%; percentages are of the nominal dose). Haussermann et al. [40] investigated the lung deposition of the HFA solution pMDI long-acting $\beta$-agonist (LABA) formoterol $(0.8 \mu \mathrm{m})$ in healthy subjects ( $\mathrm{n}=6, \mathrm{FEV}_{1} 107 \%$ of predicted), asthmatics $(\mathrm{n}=6$, $\mathrm{FEV}_{1} 72 \%$ of predicted) and COPD patients $\left(\mathrm{n}=6, \mathrm{FEV}_{1}\right.$ $40 \%$ of predicted). Total lung deposition was comparable between healthy subjects (31\%), asthmatics (34\%) and COPD patients (35\%). In both these studies with HFA$\mathrm{BDP} /$ formoterol [39] and HFA formoterol [40], no correlation was observed between baseline pulmonary function and the lung deposition in the healthy subjects, asthmatics or COPD patients. These findings are of significance as it has been thought that with increasing lung disease severity, the structural changes causing the airways to narrow lead to an overall decrease in lung deposition $[41,42]$. The data above would suggest that smallerparticle aerosols may be able to overcome one of the key patient factors influencing the lung deposition of medical aerosols and, as such, allow aerosolised medicine to reach the lungs even when they become progressively obstructed as disease severity worsens.

\section{Distal-Airway Deposition}

Probably the most significant feature of the small-particle HFA solution formulation aerosols has been the observation of a change in the pattern of drug deposition and regional-airway distribution within the lungs compared to existing larger-particle aerosols, such that smaller particles are able to penetrate more deeply into the peripheral lung. In the study reported above comparing the HFA suspension combination aerosol of $\mathrm{FP} /$ salmeterol $(2.7 \mu \mathrm{m})$ to the HFA solution corticosteroid aerosol of
BDP $(0.7 \mu \mathrm{m})$ in patients with asthma, two-dimensional $\gamma$-scintigraphy was used to assess regional-airway drug deposition in the central (C) and peripheral (P) lung [36]. It was observed that the smaller aerosol particles were able to penetrate deeper into the peripheral lung region $(\mathrm{C} / \mathrm{P}$ ratio: 1.6$)$ in contrast to the larger particle aerosols (C/P ratio: 4.9 ), which showed a more proximal central region deposition pattern. The regional-airway deposition of the HFA solution combination aerosol of BDP/ formoterol $(1.5 \mu \mathrm{m})$ has also been studied in asthmatic patients using two-dimensional $\gamma$-scintigraphy where $\sim 1 / 3$ of the drug was deposited in the peripheral lung region and $\sim 2 / 3$ in the central airways [43]. In the study by De Backer et al. [39], C/P ratios of the HFA solution BDP/ formoterol $(1.37 \mu \mathrm{m})$ were assessed in healthy subjects (1.42), asthmatics (1.96) and COPD (1.94) patients. Although the $\mathrm{C} / \mathrm{P}$ ratio was higher with greater airway obstruction $(\mathrm{C} / \mathrm{P}$ ratios of asthma and COPD patients exceeded that of healthy controls) and statistically significant differences were noted between asthmatics and healthy subjects (suggesting a more central lung region shift of drug in asthmatics), by contrast it was observed that the $\mathrm{C} / \mathrm{P}$ ratio was lower in the more obstructed COPD patients $\left(\mathrm{FEV}_{1} 44 \%\right.$ of predicted) compared to the asthmatics ( $\mathrm{FEV}_{1} 75 \%$ of predicted) and was not statistically significant between COPD patients and healthy subjects. An explanation for this latter finding was the observation in their study of greater heterogeneity of drug deposition in the COPD patients compared with the healthy subjects. These data support that the often held belief of severe airway obstruction leading to a significant redistribution of the regional aerosol deposition of inhaled drug within the lungs with a substantially more proximal airway deposition pattern may not be that important with the use of smaller-particle aerosols, which allow the inhaled drug to reach the peripheral lung region in such conditions.

The disadvantage with the imaging technique of twodimensional $\gamma$-scintigraphy is that the three-dimensional lung structure has to be 'collapsed' onto two-dimension planar images and, thereby, overlying small peripheral airways may be included in the analysis of the central lung region. To circumvent this difficulty, three-dimensional imaging in the form of single-photon emission computed tomography (SPECT) has been utilised, which gives better spatial resolution to assess the regional airways. SPECT imaging was utilised in the above-described study involving healthy volunteers $(\mathrm{n}=6)$ and small-particle corticosteroid aerosols of HFA-CIC $(1.1 \mu \mathrm{m})$, which were observed to be sufficiently distributed to both the central, intermediate and peripheral lung regions in equal 
proportions (30, 36 and, 34\%, respectively) [32]. Newman et al. [37] also analysed the regional-airway distribution of HFA-CIC $(1.1 \mu \mathrm{m})$ in patients with asthma $(\mathrm{n}=12)$ using SPECT imaging and a 'shell contour', dividing the lungs into six regions of interest. The authors observed good drug distribution throughout the airways with $44 \%$ central lung deposition (first four lung 'shell' regions) and $56 \%$ peripheral-airway deposition. Although the role of small-airway inflammation and remodelling in the pathophysiology of asthma is not yet fully understood, the data above show the technological advances that have been achieved within aerosolised medicine to allow inhaled therapy to potentially target the pathophysiology and inflammation in both the central and peripheral lung regions. Certainly, there is evidence to support asthmatic inflammation is not just confined to the large airways, but also present in the small airways [1], and it would seem intuitive that there is a need to treat both the large and small airways; that is, inhaled therapy should be distributed throughout the airway tree.

\section{Clinical Relevance of Small-Airway-Targeted Therapy}

So what does this all mean for the patient? Patients do not report an improvement or worsening in their physiological indices when they see their physician but rather what matters to them is how the disease - or indeed the therapy - impacts on their symptoms, exercise capacity and quality of life. What is the link between physiology (function) and pharmacology (treatment), and how does small-airway drug targeting relate to patient-centred clinical outcomes? Although few in number, some studies are now addressing these questions to help us understand the clinical implications of inhaled therapy targeting the periphery in patients with asthma and COPD.

\section{Asthma Control}

The effect of small- versus large-particle aerosols of ICS on small-airway function and asthma control were recently studied [44]. Hoshino et al. [44] recruited mild persistent asthmatics $(\mathrm{n}=30)$ who were treated for 2 months during a run-in phase with DPI-FP $100 \mu \mathrm{g}$ twice daily $(5.4 \mu \mathrm{m})$ and then randomised for a further 2 months to either continue to receive DPI-FP $100 \mu \mathrm{g}$ twice daily or receive HFA solution pMDI aerosol of CIC 200 $\mu \mathrm{g}$ once daily $(1.1 \mu \mathrm{m})$. No significant changes in the spirometry indices of $\mathrm{FEV}_{1}$, forced expiratory flow (FEF) and maximum expiratory flow were observed with either treatment arm during the study. However, in contrast to the large-particle aerosols of FP, the small-particle aerosols of CIC significantly improved impulse oscillometry markers of small-airway resistance $(\mathrm{R} 5-\mathrm{R} 20 \mathrm{~Hz})$ and distal reactance $(\mathrm{X} 5 \mathrm{~Hz})$, and small-particle aerosols significantly reduced the percentage of eosinophils in latephase induced sputum. Of further interest, HFA-CIC was also able to significantly improve symptoms and asthma control in patients compared to DPI-FP.

This study highlights some interesting observations. Firstly, it supports the notion that traditional spirometric markers of asthma are insensitive to assess the effects of peripherally targeted aerosols [45]. Usmani et al. [45] have observed that $\mathrm{FEF}_{25-75}, \mathrm{FEV}_{1}$ and peak expiratory flow were unable to assess the deposition effects of monodisperse aerosols of the small-particle $(1.5 \mu \mathrm{m})$, shortacting $\beta$-agonist salbutamol that preferentially targeted the small airways, whereas $\mathrm{FEV}_{1}$ was better able to detect bronchodilator changes with the larger $(6-\mu \mathrm{m})$ aerosols that targeted the proximal larger airways [45]. Secondly, Hoshino [44] demonstrated the effect of small particles on physiological markers of small-airway disease. Indices obtained from impulse oscillometry have been utilised to assess small-airway dysfunction, including frequencydependent changes in resistance between R 5 and R $20 \mathrm{~Hz}$ (R5-R20) and capacitive reactance at $5 \mathrm{~Hz}$ (X5) [46, 47]. Fahy et al. [48] have demonstrated that induced sputum obtained in the early phase after inhalation of hypertonic saline samples the proximal airways, whereas, in contrast, late-phase sputum reflects sampling of the peripheral airways. The beneficial effects of CIC on these smallairway markers may be related to the fact that the small-particle corticosteroid aerosols are able to preferentially reach the distal airways [37], unlike the larger-particle aerosols of FP. Finally, and of great interest, Hoshino [44] observed that the effects of CIC on small airway pulmonary function and lung inflammation were translated into an effect on patient-centred outcomes; in that, asthma control test scores were significantly improved after patients were switched to the CIC treatment arm after the FP run-in phase, but not in those that continued FP treatment.

\section{Stepping Down Inhaled Corticosteroids and Asthma Control}

Most asthma guidelines advocate stepping down ICSs once patients are controlled and stable on their current therapy $[49,50]$. However, it is recognised that although stepping down therapy is recommended, it is often not implemented, leading some patients to be over-treated 
with corticosteroids. Physicians acknowledge patients should be maintained on the lowest dose of ICS that achieves maximal clinical benefit and minimises adverse effects, a principle that applies to any medication used in clinical practice. The British Thoracic Society guidelines advocate health care practitioners consider reductions in the ICS dose in stable asthma patients every 3 months, and specify the dose of ICS should be reduced by $25-50 \%$ [50].

This latter recommendation is based on a prospective 1-year, double-blind, randomized, controlled trial of stepping down ICS in stable asthmatic patients in primary care [51]. In this step-down study by Hawkins et al. [51] , family practitioners in Scotland recruited 259 stable, well-controlled adult asthmatic patients receiving regular medium- to high-dose ICS treatment (mean daily dose of 1,430 $\mu \mathrm{g}$ beclomethasone) and allocated them to two parallel groups: no alteration in treatment (control group) or active reduction of their ICS (step-down group). The authors achieved a reduction in the ICS in the stepdown patients of $348 \mu \mathrm{g}$ per day without clinically significant differences in asthma exacerbations, visits to the family practitioner or oral corticosteroid use in contrast to the control group (no treatment alteration). The authors concluded that by adopting a step-down approach to the use of high-dose ICS in asthma, a reduction in the drug dose could be achieved without compromising asthma control. In a step-down ICS study undertaken in secondary care, Lee et al. [52] observed that stepping down ICS therapy in stable asthmatics was not being routinely adopted and in those patients in whom step-down therapy was implemented, no deterioration in asthma control occurred.

The step-down approach of inhaled therapy and its effect on asthma control have been investigated in a small number of studies using conventional large-particle inhalers. Collectively, the studies have supported the notion that stable asthmatic patients on high-dose ICS may be over-treated and that reductions in the inhaled dose can be achieved without worsening disease control [53-57].

\section{Small-Particle Aerosols and Stepping Down ICS}

The role of new HFA solution small-particle aerosols in the step-down management approach of asthma has recently been studied using the corticosteroids BDP, CIC and, also, the BDP/formoterol drug combination. Fowler et al. [58] stabilised moderate-to-severe uncontrolled asthmatic patients $(\mathrm{n}=39)$ with high-dose ICS (BDP $1,000 \mu \mathrm{g}$ twice daily via a DPI) for 4 weeks and then randomised their patients to either step down to a fixed-dose combination DPI inhaler (FP/salmeterol 100/50 $\mu \mathrm{g}$ twice daily; $\mathrm{n}=19$ ) or to step down to a small particle HFA solution pMDI aerosol of corticosteroid alone (BDP $200 \mu \mathrm{g}$ twice daily; $\mathrm{n}=20$ ) for 8 weeks. The authors observed that in the step-down combination treatment arm, there were improvements in methacholine bronchoprotection, lung function (determined by $\mathrm{FEV}_{1}$ and peak expiratory flow) and the asthma quality-of-life questionnaire (symptoms and emotions) compared to stepping down to the smallparticle aerosol corticosteroid. This observation could be explained by the fact that the study endpoints of bronchial provocation and lung function were more selective to assess changes in the proximal large airways where the fixed-dose large-particle combination therapy would have predominantly deposited [59], rather than assess changes in the distal small airways where the small-particle aerosol with a greater fine-particle fraction would have preferentially deposited [60].

In the study by Bateman et al. [61], the effectiveness of the small-particle aerosol of HFA-pMDI corticosteroid CIC to reduce the use of oral corticosteroids in steroiddependent patients with severe persistent asthma was investigated. The lowest effective dose of oral prednisone was established for each patient before randomisation at which their current ICSs were discontinued, and patients were treated in three parallel groups to receive either CIC 320 or $640 \mu \mathrm{g}$ twice daily, or placebo for 3 months. Both doses of CIC significantly reduced prednisone use (47 and $63 \%$ for CIC 640 and 1,280 $\mu$ g daily, respectively) whilst maintaining asthma control in patients (determined using a 24-hour asthma symptom rating score). In contrast, probably unsurprisingly, the use of oral corticosteroids increased in the placebo group ( $4 \%$ increase). Interestingly, $30 \%$ of all patients treated with CIC were able to completely stop prednisone. As commented above, oral corticosteroids, through their systemic delivery to the lungs, are able to treat asthmatic inflammation in both the large and also the small airways, which has clearly been shown to be present in patients with severe asthma $[1,62]$. However, oral corticosteroids are associated with significant adverse effects. The study by Bateman et al. [61] demonstrated that by using the inhaled route to deliver a small-particle aerosol of corticosteroid to target small (and large)-airway inflammation allowed patients to reduce or discontinue their oral prednisolone without worsening asthma control [61]. This study shows that small-particle aerosols of corticosteroids can achieve reductions in oral corticosteroid usage and allow discontinuation of oral corticosteroid in patients with severe asthma in a similar approach to studies reported using 
the ICSs of DPI-FP and DPI-BUD that have larger aerosol particle size $[63,64]$.

Papi et al. [65] recently reported the first study to assess asthma control after step-down of treatment based on the GINA guidelines comparing the small-particle HFA solution combination aerosol of $\mathrm{BDP} /$ formoterol to the DPI combination of $\mathrm{FP} /$ salmeterol. In a prospective, 6-month, parallel trial, asthmatic patients $(\mathrm{n}=378)$ controlled for 2 months on fixed high-dose DPI-FP/salmeterol $(1,000 / 100 \mu \mathrm{g}$ daily) during run-in were randomised to step down to either the DPI FP/salmeterol (500/100 $\mu \mathrm{g}$ daily) that was half the corticosteroid dose compared to run-in or to a small-particle HFA-BDP/formoterol (400/24 $\mu \mathrm{g}$ daily), where the ICS dose of BDP $(400 \mu \mathrm{g})$ was kept equivalent to the ICS dose in the arm of the parallel step-down treatment with FP $(500 \mu \mathrm{g})$. Compared to the ICS dose at the end of the run-in phase, a significant reduction in the weekly mean ICS dose was noted in both the DPI-FP/salmeterol group (51\% ICS dose reduction) and the HFA-BDP/formoterol group (62\% ICS dose reduction). The cumulative mean ICS dose during the 6-month study period was significantly lower in the HFA$\mathrm{BDP} /$ formoterol group compared to the DPI-FP/salmeterol group. The authors observed that in the primary outcome of morning peak expiratory flow, the small-particle aerosol HFA-pMDI combination showed equivalent efficacy to the larger-particle DPI combination. It was also noted that the small-particle combination aerosols achieved asthma control to similar levels compared to the large-particle combination inhaler and that the small particles achieved reductions in the ICS dose without worsening disease control; in that, over $90 \%$ of patients stepped down to either treatment arm continued to remain controlled or partially controlled according to GINA criteria.

The recent interest in 'real-life' research reflects the importance of understanding how data from selected patients enrolled in clinical trials are representative to that of a real-life population of 'unselected' patients [66, 67]. In a real-life observational study involving 2,853 adult asthmatic patients from hospital respiratory units in Italy, the prevalence of asthma control and its relationship to health care resource consumption was investigated [68]. The authors observed $19.8 \%$ of the patients were uncontrolled, $15.8 \%$ were partially controlled and $64.4 \%$ had controlled asthma based on the asthma control test. Of the patients $(n=1,380)$ treated with an ICS/LABA combination inhaler for a minimum of 4 weeks, $14.2 \%$ were uncontrolled, $13.7 \%$ were partially controlled and $72.1 \%$ had controlled asthma. Of the 1,380 patients as- sessed for asthma control, 454 patients were treated with $\mathrm{BDP} /$ formoterol, 453 with $\mathrm{BUD} /$ formoterol and 473 with $\mathrm{FP} / \mathrm{salmeterol}$. The proportion of controlled asthma was significantly higher in those patients given the small-particle aerosol of $\mathrm{BDP} /$ formoterol ( $76 \%$ controlled) than in those treated with BUD/formoterol (69\% controlled), and at similar levels compared to $\mathrm{FP} /$ salmeterol $(71 \%$ controlled). The mean daily ICS dose was lower for the smallparticle aerosol of BDP/formoterol compared to BUD/ formoterol and to FP/salmeterol (311.7 vs. 590.1 vs. 675.3 $\mu \mathrm{g}$, respectively), with a significantly better health-related quality-of-life status achieved with small-particle $\mathrm{BDP} /$ formoterol compared to $\mathrm{FP} /$ salmeterol, and similar levels compared to BUD/formoterol.

\section{Small-Particle Aerosols and COPD}

Recently, the role of small-particle aerosols on patientcentred outcomes has also been investigated in patients with COPD. In a randomised, double-blind, doubledummy, parallel, 3-month study, Tzani et al. [69] evaluated the effects of the small-particle HFA solution pMDI combination aerosol BDP/formoterol (400/24 $\mu \mathrm{g}$ daily) and the DPI-FP/salmeterol combination $(500 / 100 \mu \mathrm{g}$ daily) on air trapping, lung hyperinflation and dyspnoea in 18 patients with severe stable COPD. Compared to baseline values, the small particles of HFA-BDP/formoterol achieved a significant reduction in the air-trapping physiological indices of residual volume (RV), total lung capacity (TLC) and functional residual capacity, which was not achieved with the DPI-FP/salmeterol combination. Comparing HFA-BDP/formoterol treatment to DPI-FP/ salmeterol, a significantly greater reduction in RV was observed with the small-particle HFA aerosols. Interestingly, not only did this study explore the relationship between the effect of two different formulations of combination therapy on physiological variables, but also their association with patient-centred outcomes. HFA-BDP/ formoterol significantly improved the transition dyspnoea index total score compared to DPI-FP/salmeterol and, importantly, the improvement in dyspnoea reported by the patients was above the clinically relevant threshold only with the small-particle aerosols of HFA-BDP/formoterol [70]. The authors reasoned that the small particles and greater fine-particle fraction with the HFA-BDP/ formoterol aerosol would allow the drug to preferentially reach the small airways compared to a large-sized aerosol allowing an effect on distal air trapping, which was observed to translate into patient benefit. Indeed, this would seem plausible as the small airways are recognised as the major site of airflow limitation in COPD [71, 72], and 
peripheral-airway obstruction is known to cause progressive air trapping during expiration with limitation of exercise capacity in COPD patients [73]. The data by Tzani et al. [69] are consistent with the observation that parameters of hyperinflation show better correlation with patient-centred health outcomes than the $\mathrm{FEV}_{1}$ [74].

The recent study by Calverley et al. [75] in patients with COPD, although not significant in its co-primary endpoints of $\mathrm{FEV}_{1}$ and disease exacerbation, provides insight into the role of small-particle HFA combination aerosol therapy in (i) molecular drug interactions, (ii) small-airway physiological assessment and (iii) translation of small-airway-directed therapy into patient-centred outcomes. In a large, randomized, controlled study, Calverley et al. [75] investigated the effect of combination ICS/LABA treatment delivered as small-particle HFApMDI aerosol versus larger-particle DPI delivery on pulmonary function, respiratory symptoms and disease exacerbation in severe stable COPD patients $(n=703)$ [75]. After a run-in phase of 4 weeks with the ipratropium bromide/salbutamol combination $(40 / 200 \mu \mathrm{g}$, three times a day), patients were randomised to three parallel groups of treatment with HFA-pMDI BDP/formoterol (200/12 $\mu \mathrm{g}$, twice daily), DPI BUD/formoterol (400/12 $\mu$ g, twice daily) or DPI formoterol alone (12 $\mu \mathrm{g}$, twice daily) for 48 weeks. Both the small-particle HFA-pMDI combination aerosol and the DPI combination treatment showed comparable efficacy in the change (at 48 weeks vs. baseline) of the pre-dose morning $\mathrm{FEV}_{1}$, which was achieved with the small-particle aerosols despite the lower daily ICS in the HFA-pMDI aerosol. The study also indicated that the small-particle HFA combination aerosol showed a significantly greater improvement in $\mathrm{FEV}_{1}$ compared to the DPI-LABA treatment alone, an effect which was also observed with the DPI combination inhaler. This probably reflected the additional contribution of the anti-inflammatory effect of the corticosteroid in the combination formulations over and above single-agent LABA treatment [76]. Indeed, there is growing evidence for the molecular rationale of the complementary interactions and effects between corticosteroids and LABA both in vitro [77-80] and in vivo [81-84], where studies have shown that corticosteroids up-regulate $\beta$-receptors and LABAs increase glucocorticoid receptor translocation and uptake into the nucleus. This molecular basis may explain the improvement in lung function and symptoms, and effects on disease exacerbation in both asthma and COPD achieved with the combination treatment compared with either drug alone in large clinical trials [85-91]. These data on a complementary clinical effect between cortico-

Treating the Small Airways steroid and LABA using small-particle aerosols is also consistent with a previous observation using small-particle aerosols in asthma, where the HFA-pMDI BDP/formoterol combination achieved significantly greater asthma control than either BDP or formoterol alone [92].

Of interest with respect to small-airway therapy was the finding by Calverley et al. [75] that though all treatments improved forced vital capacity (FVC), this improvement was only significant with the small-particle HFA-pMDI aerosol treatment. FVC has been used as an indirect indicator of small-airway function, where an improvement in FVC may indicate a reduction in airway closure and air trapping [3]. In the Severe Asthma Research Program, Sorkness et al. [93] observed marked physiological air trapping in the cohort with severe asthma ( $\mathrm{n}=$ $287)$ compared to the non-severe asthmatics $(n=383)$, with a significant increase in RV, TLC, functional residual capacity and the RV/TLC ratio as a percentage of predicted values in the severe asthmatics. The investigators noted a strongly significant inverse correlation of FVC percentage predicted with the RV/TLC ratio percentage predicted, giving support to FVC as an indirect spirometric surrogate of air trapping. Interestingly, in the same study cohort, the authors found that the $\mathrm{FEF}_{25-75}$ showed a poor correlation with the RV/TLC ratio percentage predicted. These observations again highlight the fact previously discussed that traditional spirometry is insensitive to detect effects on the peripheral airways [45]. The effect on FVC using the small-particle aerosols of HFA-BDP/ formoterol has also been observed in moderate-to-severe asthmatic patients. In a study by Papi et al. [94], FVC significantly improved with HFA solution pMDI BDP/formoterol (400/24 $\mu \mathrm{g}$ daily) compared to HFA suspension pMDI FP/salmeterol (500/100 $\mu$ g daily) after 3 months of treatment leading to the conclusion that the improvement in FVC reflected a reduction in air trapping and smallairway obstruction. Both the consistent observations in FVC improvement in the study by Calverley et al. [75] in COPD patients and the study by Papi et al. [94] in asthmatic patients may be explained by the greater peripheralairway deposition of the smaller-particle $(1.5 \mu \mathrm{m})$ HFA solution $\mathrm{BDP} /$ formoterol aerosol [43] in contrast to the relatively more central-airway deposition of the largerparticle $(2.7 \mu \mathrm{m})$ HFA suspension $\mathrm{FP} /$ salmeterol aerosol and $(4.0 \mu \mathrm{m}) \mathrm{DPI} B \mathrm{BU} /$ formoterol $[27,36]$. The findings related to FVC are interesting and require further investigation and validation, as with other physiological markers [95], particularly as this spirometric marker is easily accessible and measurable in primary care and could help in the day-to-day control and management of patients 
with asthma and COPD, tantalisingly identifying those patients with small-airway involvement $[1,2]$.

The study by Calverley et al. [75] of small-particle aerosols in COPD also highlights the translation of smallairway-directed therapy into the clinical scenario with respect to patient-centred outcomes. A co-primary endpoint in the study was the mean rate of disease exacerbations per patient per year. It is recognised that the frequency of disease exacerbations contributes to long-term lung function decline in patients with COPD [96]. It was surprising that there was no difference between the three treatment groups regarding this endpoint, and the authors attributed this to potential bias in the inclusion criteria of their study, where closer disease monitoring leading to better symptom management as part of a clinical trial may have resulted in an overall lower disease exacerbation in the studied cohort. However, in contrast, at 48 weeks of assessment, in all three treatment groups the 6-min walking distance was significantly improved compared to baseline measurements, and the greatest improvement occurred in the group with the small-particle aerosols of HFA-BDP/formoterol. Of further note, only the small-particle aerosol achieved an improvement in the 6-min walking distance that was above the clinically relevant threshold of $37 \mathrm{~m}$ [97]. This improvement in daily activity could be attributable to the peripheral deposition of the small-particle aerosol and its physiological effects on dynamic hyperinflation and distal-airway air trapping $[3,98]$. This finding encourages us to acknowledge the important notion of the 'minimal clinically important difference' with respect to outcome measures or physiological endpoints in clinical trials and to understand what the relationship is between a given change in the magnitude in any one of these outcomes with respect to the clinical importance to health care professionals or to the perceptible meaningfulness by the patient [99102]. This is equally important for measures of small airways as it is for the established physiological measures of large-airway bronchodilation.

\section{Concluding Remarks}

The last decade has seen greater confidence in our ability to utilise physiological techniques and imaging modalities to assess small-airway structure and function $[3,103]$, which have been coupled with technological advances in inhaled drug delivery that now allow us to deliver aerosolised medicine to the small airways. Thus, we can now use these tools and treatments, and take up the challenge to prove (or disprove!) the hypothesis that inhaled drug delivery to the small airways is clinically beneficial and translates into improved patient outcome in asthma and COPD. Recent times have also heralded clinical trials of bronchoscopic surgical techniques where interventions undertaken within the large airways may indirectly treat the pathophysiological consequences of small-airway disease in COPD [104]; larger patient trials and prospective long-term follow-up are needed here. Finally, our allergy, rhinology and ENT colleagues remind us not to forget the 'one-airway hypothesis' and to treat inflammation in the 'top part' of the respiratory tract; where treating allergic rhinitis has been shown to translate into improved overall asthma control [105]. Maybe we should not forget to treat the 'bottom part' of the respiratory tract either: the overlooked 'silent' small airways, so that we wholly manage the mucosal carpet of inflammation in the 'unified-airway' paradigm [106]. These truly are exciting times for all researchers involved in unravelling the mysteries of the small airways [107].

\section{Acknowledgements}

Dr. Omar S. Usmani is a recipient of an NIHR (National Institute for Health Research) Career Development Fellowship and supported by the NIHR Respiratory Disease Biomedical Research Unit at the Royal Brompton and Harefield NHS Foundation Trust and Imperial College London, UK.

\section{References}

1 Hamid Q: Pathogenesis of small airways in asthma. Respiration 2012;84:4-11.

2 Baraldo S, Turato G, Saetta M: Pathophysiology of the small airways in chronic obstructive pulmonary disease. Respiration 2012;84: $89-97$.

3 Verbanck S: Physiological measurement of the small airways. Respiration 2012;84:177188 . in 't Veen JC, Beekman AJ, Bel EH, Sterk PJ: Recurrent exacerbations in severe asthma are associated with enhanced airway closure during stable episodes. Am J Respir Crit Care Med 2000;161:1902-1906.

5 Wagner EM, Liu MC, Weinmann GG, Permutt S, Bleecker ER: Peripheral lung resistance in normal and asthmatic subjects. Am Rev Respir Dis 1990;141:584-588.
Hyde DM, Hamid Q, Irvin CG: Anatomy, pathology, and physiology of the tracheobronchial tree: emphasis on the distal airways. J Allergy Clin Immunol 2009;124(6 suppl): S72-S77.

7 Kraft M, Djukanovic R, Wilson S, Holgate ST, Martin RJ: Alveolar tissue inflammation in asthma. Am J Respir Crit Care Med 1996; 154:1505-1510. 
8 Kraft M, Pak J, Martin RJ, Kaminsky D, Irvin CG: Distal lung dysfunction at night in nocturnal asthma. Am J Respir Crit Care Med 2001;163:1551-1556.

-9 Kaminsky DA, Irvin CG, Gurka DA, Feldsien DC, Wagner EM, Liu MC, Wenzel SE: Peripheral airway responsiveness to cool, dry air in normal and asthmatic individuals. Am J Respir Crit Care Med 1995;152:1784-1790.

10 Berry M, Hargadon B, Morgan A, Shelley M, Richter J, Shaw D, Green RH, Brightling C, Wardlaw AJ, Pavord ID: Alveolar nitric oxide in adults with asthma: evidence of distal lung inflammation in refractory asthma. Eur Respir J 2005;25:986-991.

- 11 Fritscher LG, Rodrigues MT, Zamel N, Chapman KR: The effect of montelukast on exhaled nitric oxide of alveolar and bronchial origin in inhaled corticosteroid-treated asthma. Respir Med 2009;103:296-300.

12 Gandevia B: Historical review of the use of parasympatholytic agents in the treatment of respiratory disorders. Postgrad Med J 1975; 51(7 suppl):13-20.

13 Grossman J: The evolution of inhaler technology. J Asthma 1994;31:55-64.

14 Dalby R, Suman J: Inhalation therapy: technological milestones in asthma treatment. Adv Drug Deliv Rev 2003;55:779-791.

15 Hanania NA, Wittman R, Kesten S, Chapman KR: Medical personnel's knowledge of and ability to use inhaling devices. Metereddose inhalers, spacing chambers, and breathactuated dry powder inhalers. Chest 1994; 105:111-116.

- 16 Plaza V, Sanchis J, Roura P, Molina J, Calle M, Quirce S, Viejo JL, Caballero F, Murio C: Physicians' knowledge of inhaler devices and inhalation techniques remains poor in Spain. J Aerosol Med Pulm Drug Deliv 2012; 25:16-22.

-17 Zainudin BM, Biddiscombe M, Tolfree SE, Short M, Spiro SG: Comparison of bronchodilator responses and deposition patterns of salbutamol inhaled from a pressurised metered dose inhaler, as a dry powder, and as a nebulised solution. Thorax 1990;45:469-473.

$\checkmark 18$ Labiris NR, Dolovich MB: Pulmonary drug delivery. Part I: physiological factors affecting therapeutic effectiveness of aerosolized medications (review). Br J Clin Pharmacol 2003;56:588-599.

19 Gerrity TR, Lee PS, Hass FJ, Marinelli A, Werner P, Lourenço RV: Calculated deposition of inhaled particles in the airway generations of normal subjects. J Appl Physiol 1979;47:867-873.

20 Heyder J: Assessment of airway geometry with inert aerosols. J Aerosol Med 1989;2: 89-97.

21 Chrystyn H: Anatomy and physiology in delivery: can we define our targets? Allergy 1999;54(suppl 49):82-87.
22 Usmani OS, Biddiscombe MF, Barnes PJ: Regional lung deposition and bronchodilator response as a function of beta2-agonist particle size. Am J Respir Crit Care Med 2005; 172:1497-1504

23 Molina MJ, Rowland FS: Stratospheric sink for chlorofluoromethanes: chlorine atomcatalysed destruction of ozone. Nature 1974; 249:810-812.

24 Dolovich M: New delivery systems and propellants. Can Respir J 1999;6:290-295.

25 Zeidler M, Corren J: Hydrofluoroalkane formulations of inhaled corticosteroids for the treatment of asthma. Treat Respir Med 2004; 3:35-44.

26 Derendorf H, Nave R, Drollmann A, Cerasoli F, Wurst W: Relevance of pharmacokinetics and pharmacodynamics of inhaled corticosteroids to asthma. Eur Respir J 2006; 28:1042-1050.

27 Martin RJ: Therapeutic significance of distal airway inflammation in asthma. J Allergy Clin Immunol 2002;109(2 suppl):S447-S460.

28 Yang TT, Li S, Wyka B, Kenyon D: Drug de livery performance of the mometasone $\mathrm{fu}$ roate dry powder inhaler. J Aerosol Med 2001;14:487-494.

29 Cripps A, Riebe M, Schulze M, Woodhouse R: Pharmaceutical transition to non-CFC pressurized metered dose inhalers. Respir Med 2000;94(suppl B):S3-S9.

30 Acerbi D, Brambilla G, Kottakis I: Advances in asthma and COPD management: delivering CFC-free inhaled therapy using Modulite technology. Pulm Pharmacol Ther 2007; 20:290-303.

31 Leach CL, Davidson PJ, Boudreau RJ: Improved airway targeting with the CFC-free HFA-beclomethasone metered-dose inhaler compared with CFC-beclomethasone. Eur Respir J 1998;12:1346-1353.

32 Leach CL, Bethke TD, Boudreau RJ, et al: Two-dimensional and three-dimensional imaging show ciclesonide has high lung deposition and peripheral distribution: a nonrandomized study in healthy volunteers. J Aerosol Med 2006;19:117-126.

33 de Vries TW, Rottier BL, Gjaltema D, Hagedoorn P, Frijlink HW, de Boer AH: Comparative in vitro evaluation of four corticosteroid metered dose inhalers: consistency of delivered dose and particle size distribution. Respir Med 2009;103:1167-1173.

34 Lewis D, Brambilla G, Church T, Meakin B: Beclomethasone dipropionate and formoterol association within a combination HFA solution MDI. Respir Drug Deliv 2006;3:939942.

35 Leach CL, Davidson PJ, Hasselquist BE, Boudreau RJ: Lung deposition of hydrofluoroalkane-134a beclomethasone is greater than that of chlorofluorocarbon fluticasone and chlorofluorocarbon beclomethasone: a cross-over study in healthy volunteers. Chest 2002;122:510-516.
36 Leach CL, Kuehl PJ, Chand R, Ketai L, Norenberg JP, McDonald JD: Characterization of respiratory deposition of fluticasone-salmeterol hydrofluoroalkane-134a and hydrofluoroalkane-134a beclomethasone in asthmatic patients. Ann Allergy Asthma Immunol 2012;108:195-200.

- 37 Newman S, Salmon A, Nave R, Drollmann A: High lung deposition of ${ }^{99 \mathrm{~m}} \mathrm{Tc}$-labeled ciclesonide administered via HFA-MDI to patients with asthma. Respir Med 2006;100: 375-384.

38 Verbanck S, Kalsi HS, Biddiscombe MF, Agnihotri V, Belkassem B, Lacor C, Usmani OS: Inspiratory and expiratory aerosol deposition in the upper airway. Inhal Toxicol 2011;23:104-111.

39 De Backer W, Devolder A, Poli G, Acerbi D, Monno R, Herpich C, et al: Lung deposition of $\mathrm{BDP} /$ formoterol HFA pMDI in healthy volunteers, asthmatic, and COPD patients. J Aerosol Med Pulm Drug Deliv 2010;23:137148.

40 Häussermann S, Acerbi D, Brand P, Herpich C, Poli G, Sommerer K, Meyer T: Lung deposition of formoterol HFA (Atimos/Forair) in healthy volunteers, asthmatic and COPD patients. J Aerosol Med 2007;20:331-341.

41 Laube BL, Swift DL, Wagner HN, Norman PS, Adams GK: The effect of bronchial obstruction on central airway deposition of a saline aerosol in patients with asthma. Am Rev Respir Dis 1986;133:740-743.

42 Richards R, Haas A, Simpson S, Britten A, Renwick A, Holgate S: Effect of methacholine induced bronchoconstriction on the pulmonary distribution and plasma pharmacokinetics of inhaled sodium cromoglycate in subjects with normal and hyperreactive airways. Thorax 1988;43:611-616.

-43 Nicolini G, Scichilone N, Bizzi A, Papi A, Fabbri LM: Beclomethasone/formoterol fixed combination for the management of asthma: patient considerations. Ther Clin Risk Manag 2008;4:855-864

44 Hoshino M: Comparison of effectiveness in ciclesonide and fluticasone propionate on small airway function in mild asthma. Allergol Int 2010;59:59-66.

-45 Usmani OS, Biddiscombe MF, Nightingale JA, Underwood SR, Barnes PJ: Effects of bronchodilator particle size in asthmatic patients using monodisperse aerosols. J Appl Physiol 2003;95:2106-2112.

46 Goldman MD, Saadeh C, Ross D: Clinical applications of forced oscillation to assess peripheral airway function. Respir Physiol Neurobiol 2005;148:179-194.

- 47 Paredi P, Goldman M, Alamen A, Ausin P, Usmani OS, Pride NB, Barnes PJ: Comparison of inspiratory and expiratory resistance and reactance in patients with asthma and chronic obstructive pulmonary disease. Thorax 2010;65:263-267. 
-48 Fahy JV, Wong H, Liu J, Boushey HA: Comparison of samples collected by sputum induction and bronchoscopy from asthmatic and healthy subjects. Am J Respir Crit Care Med 1995;152:53-58.

49 Global Initiative for Asthma (GINA): GINA Report, Global Strategy for Asthma Management and Prevention, revised 2011. http:// www.ginasthma.org/.

50 British Thoracic Society (BTS) and Scottish Intercollegiate Guidelines Network (SIGN): British Guideline on the Management of Asthma, revised 2012. http://www.britthoracic.org.uk/guidelines/asthma-guidelines.aspx.

-51 Hawkins G, McMahon AD, Twaddle S, Wood SF, Ford I, Thomson NC: Stepping down inhaled corticosteroids in asthma: randomised controlled trial. BMJ 2003;326: 1115-1118.

52 Lee DK, Borade PS, Promnitz DA, Currie GP: Stepping-down inhaled corticosteroid therapy in stable asthma: a secondary care perspective. QJM 2005;98:771-772.

53 Reddel HK, Gibson PG, Peters MJ, Wark PA, Sand IB, Hoyos CM, Jenkins CR: Down-titration from high-dose combination therapy in asthma: removal of long-acting beta(2)agonist. Respir Med 2010;104:1110-1120.

54 Godard P, Greillier P, Pigearias B, Nachbaur G, Desfourgeres JL, Attali V: Maintaining asthma control in persistent asthma: comparison of three strategies in a 6-month double-blind randomised study. Respir Med 2008;102:1124-1131.

-55 Bateman ED, Jacques L, Goldfrad C, Atienza T, Mihaescu T, Duggan M: Asthma control can be maintained when fluticasone propionate/salmeterol in a single inhaler is stepped down. J Allergy Clin Immunol 2006;117: 563-570.

-56 Foresi A, Mastropasqua B, Chetta A, D'Ippolito R, Testi R, Olivieri D, Pelucchi A: Step-down compared to fixed-dose treatment with inhaled fluticasone propionate in asthma. Chest 2005;127:117-124.

- 57 Fardon T, Haggart K, Lee DK, Lipworth BJ: A proof of concept study to evaluate stepping down the dose of fluticasone in combination with salmeterol and tiotropium in severe persistent asthma. Respir Med 2007;101: 1218-1228.

58 Fowler SJ, Currie GP, Lipworth BJ: Stepdown therapy with low-dose fluticasone salmeterol combination or medium dose hydrofluoroalkane 134a-beclomethasone alone. J Allergy Clin Immunol 2002;109: 929-935.

59 Olsson B: Aerosol particle generation from dry powder inhalers: can they equal pressurized metered dose inhalers? J Aerosol Med 1995;8(suppl 3):S13-S18.

60 Leach CL: Improved delivery of inhaled steroids to the large and small airways. Respir Med 1998;92(suppl A):3-8.
61 Bateman E, Karpel J, Casale T, Wenzel S, Banerji D: Ciclesonide reduces the need for oral steroid use in adult patients with severe, persistent asthma. Chest 2006;129:1176-1187.

62 Wenzel SE, Szefler SJ, Leung DY, Sloan SI, Rex MD, Martin RJ: Bronchoscopic evaluation of severe asthma: persistent inflammation associated with high dose glucocorticoids. Am J Respir Crit Care Med 1997;156: 737-743.

63 Nelson HS, Bernstein IL, Fink J, et al: Oral glucocorticosteroid-sparing effect of budesonide administered by Turbuhaler: a double-blind, placebo-controlled study in adults with moderate-to-severe chronic asthma. Pulmicort Turbuhaler Study Group. Chest 1998;113:1264-1271.

64 Nelson HS, Busse WW, deBoisblanc BP, et al: Fluticasone propionate powder: oral corticosteroid-sparing effect and improved lung function and quality of life in patients with severe chronic asthma. J Allergy Clin Immunol 1999;103:267-275.

65 Papi A, Nicolini G, Crimi N, Fabbri L, Olivieri D, Rossi A, Paggiaro P: Step-down from high dose fixed combination therapy in asthma patients: a randomized controlled trial. Respir Res 2012;13:54.

66 Dahlén S-E, Dahlén B, Drazen JM: Asthma treatment guidelines meet the real world. $\mathrm{N}$ Engl J Med 2011;364:1769-1770.

67 Ware JH, Hamel MB: Pragmatic trials guides to better patient care? N Engl J Med 2011;364:1685-1687.

68 Allegra L, Cremonesi G, Girbino G, Ingrassia E, Marsico S, Nicolini G, Terzano C; PRISMA (PRospectIve Study on asthMA control) Study Group. Real-life prospective study on asthma control in Italy: cross-sectional phase results. Respir Med 2012;106: 205-214.

69 Tzani P, Crisafulli E, Nicolini G, Aiello M, Chetta A, Clini EM, Olivieri D: Effects of beclomethasone/formoterol fixed combination on lung hyperinflation and dyspnea in COPD patients. Int J Chron Obstruct Pulmon Dis 2011;6:503-509.

70 Mahler DA, Witek TJ Jr: The MCID of the transition dyspnea index is a total score of one unit. COPD 2005;2:99-103.

71 Hogg JC, Macklem PT, Thurlbeck WM: Site and nature of airway obstruction in chronic obstructive lung disease. N Engl J Med 1968; 278:1355-1360.

72 Barnes PJ: Small airways in COPD. N Engl J Med 2004;350:2635-2637.

73 GOLD Report Executive Summary. Global Strategy for the Diagnosis, Management, and Prevention of COPD, Global Initiative for Chronic Obstructive Lung Disease (GOLD) 2010. http://www.goldcopd.org/ guidelines-global-strategy-for-diagnosismanagement.html.
4 O’Donnell DE, Lam MIU, Webb KA: Spirometric correlates of improvement in exercise performance after anticholinergic therapy in chronic obstructive pulmonary disease. Am J Respir Crit Care Med 1999;160:542-549.

75 Calverley PM, Kuna P, Monsó E, Costantini M, Petruzzelli S, Sergio F, Varoli G, Papi A, Brusasco V: Beclomethasone/formoterol in the management of COPD: a randomised controlled trial. Respir Med 2010;104:18581868.

76 Adcock IM, Maneechotesuwan K, Usmani O: Molecular interactions between glucocorticoids and long-acting beta2-agonists (review). J Allergy Clin Immunol 2002;110(6 suppl):S261-S268.

77 Mak JC, Nishikawa M, Shirasaki H, Miyayasu K, Barnes PJ: Protective effects of a glucocorticoid on downregulation of pulmonary beta-2 adrenergic receptors in vivo. J Clin Invest 1995;96:99-106.

78 Eickelberg O, Roth M, Lorx R, Bruce V, Rudiger J, Johnson M, Block LM: Ligand-independent activation of the glucocorticoid receptor by beta 2 -adrenergic receptor agonists in primary human lung fibroblasts and vascular smooth muscle cells. J Biol Chem 1999; 274:1005-1010.

79 Roth M, Johnson PR, Rudiger JJ, King GG, Ge Q, Burgess JK, Anderson G, Tamm M, Black JL: Interaction between glucocorticoids and beta 2 agonists on bronchial airway smooth muscle cells through synchronised cellular signalling. Lancet 2002;360:12931299.

80 Papakonstantinou E, Klagas I, Karakiulakis G, Hostettler K, S'ng CT, Kotoula V, Savic S, Tamm M, Roth M: Steroids and $\beta 2$ agonists regulate hyaluronan metabolism in asthma airway smooth muscle cells. Am J Respir Cell Mol Biol 2012, E-pub ahead of print.

81 Usmani OS, Ito K, Maneechotesuwan K, Ito M, Johnson M, Barnes PJ, Adcock IM: Glucocorticoid receptor nuclear translocation in airway cells after inhaled combination therapy. Am J Respir Crit Care Med 2005; 172 : 704-712.

82 Orsida BE, Ward C, Li X, Bish R, Wilson JW, Thien F, Walters EH: Effect of a long-acting $\beta 2$-agonist over three months on airway wall vascular remodeling in asthma. Am J Respir Crit Care Med 2001;164:117-121.

83 Li X, Ward C, Thien F, Bish R, Bamford T, Bao X, Bailey M, Wilson JW, Walters EH: An antiinflammatory effect of salmeterol, a long-acting $\beta 2$ agonist, assessed in airway biopsies and bronchoalveolar lavage in asthma. Am J Respir Crit Care Med 1999;160: 1493-1499.

84 Baraniuk JN, Ali M, Brody D, et al: Glucocorticosteroids induce beta2-adrenergic receptor function in human nasal mucosa. Am J Respir Crit Care Med 1997;155:704-710. 
85 Greening AP, Ind PW, Northfield M, Shaw G: Added salmeterol versus higher-dose corticosteroid in asthma patients with symptoms on existing inhaled corticosteroid. Lancet 1994;344:219-224.

-86 Woolcock A, Lundback B, Ringdal N, Jacques LA: Comparison of addition of salmeterol to inhaled steroids with doubling of the dose of inhaled steroids. Am J Respir Crit Care Med 1996;153:1481-1488.

87 Pauwels RA, Lofdahl CG, Postma DS, Tattersfield AE, O’Byrne P, Barnes PJ, Ullman A: Effect of inhaled formoterol and budesonide on exacerbations of asthma. Formoterol and Corticosteroids Establishing Therapy (FACET) International Study Group. N Engl J Med 1997;337:1405-1411.

-88 Juniper EF, Svensson K, O’Byrne PM, Barnes PJ, Bauer CA, Lofdahl CG, Postma DS, Pauwels RA, Tattersfield AE, Ullman A: Asthma quality of life during 1 year of treatment with budesonide with or without formoterol. Eur Respir J 1999;14:1038-1043.

89 Shrewsbury S, Pyke S, Britton M: Meta-analysis of increased dose of inhaled steroid or addition of salmeterol in symptomatic asthma (MIASMA). BMJ 2000;320:1368-1373.

90 Matz J, Emmett A, Rickard K, Kalberg C: Addition of salmeterol to low-dose fluticasone versus higher-dose fluticasone: an analysis of asthma exacerbations. J Allergy Clin Immunol 2001;107:783-789.

91 Calverley PM, Anderson JA, Celli B, et al: Salmeterol and fluticasone propionate and survival in chronic obstructive pulmonary disease. N Engl J Med 2007;356:775-789.

-92 Huchon G, Magnussen H, Chuchalin A, Dymek L, Gonod FB, Bousquet J: Lung function and asthma control with beclomethasone and formoterol in a single inhaler. Respir Med 2009;103:41-49.
93 Sorkness RL, Bleecker ER, Busse WW, Calhoun WJ, Castro M, Chung KF, Curran-Everett D, Erzurum SC, Gaston BM, Israel E, Jarjour NN, Moore WC, Peters SP, Teague WG, Wenzel SE, National Heart, Lung, and Blood Institute Severe Asthma Research Program: Lung function in adults with stable but severe asthma: air trapping and incomplete reversal of obstruction with bronchodilation. J Appl Physiol 2008;104:394-403.

94 Papi A, Paggiaro P, Nicolini G, Vignola AM, Fabbri LM, ICAT SE study group: Beclomethasone/formoterol vs fluticasone/salmeterol inhaled combination in moderate to severe asthma. Allergy 2007;62:1182-1188.

95 Verbanck S, Thompson BR, Schuermans D, Kalsi H, Biddiscombe M, Stuart-Andrews C, Hanon S, Van Muylem A, Paiva M, Vincken $\mathrm{W}$, Usmani O: Ventilation heterogeneity in the acinar and conductive zones of the normal ageing lung. Thorax 2012;67:789-795.

96 Donaldson GC, Seemungal TA, Bhowmik A, Wedzicha JA: Relationship between exacerbation frequency and lung function decline in chronic obstructive pulmonary disease. Thorax 2002;57:847-852.

97 Cazzola M, MacNee W, Martinez FJ, Rabe KF, Franciosi LG, Barnes PJ, Brusasco V, Burge PS, Calverley PM, Celli BR, Jones PW, Mahler DA, Make B, Miravitlles M, Page CP, Palange P, Parr D, Pistolesi M, Rennard SI, Rutten-van Mölken MP, Stockley R, Sullivan SD, Wedzicha JA, Wouters EF, American Thoracic Society, European Respiratory Society Task Force on Outcomes of COPD: Outcomes for COPD pharmacological trials: from lung function to biomarkers. Eur Respir J 2008;31:416-469.

98 Garcia-Rio F, Lores V, Mediano O, Rojo B, Hernanz A, López-Collazo E, Alvarez-Sala R: Daily physical activity in patients with chronic obstructive pulmonary disease is mainly associated with dynamic hyperinflation. Am J Respir Crit Care Med 2009;180: 506-512.
-99 Barnes ML, Vaidyanathan S, Williamson PA, Lipworth BJ: The minimal clinically important difference in allergic rhinitis. Clin Exp Allergy 2010;40:242-250.

100 Harding G, Leidy NK, Meddis D, Kleinman L, Wagner S, O'Brien CD: Interpreting clinical trial results of patient-perceived onset of effect in asthma: methods and results of a Delphi panel. Curr Med Res Opin 2009; 25:1563-1571.

101 Meyer RJ: U.S. regulatory perspective on the minimal clinically important difference in chronic obstructive pulmonary disease. COPD 2005;2:47-49.

102 Norman GR: The relation between the minimally important difference and patient benefit. COPD 2005;2:69-73.

103 King GG: Tomographic imaging of small airways. Respiration 2012;84:265-274.

104 Gasparini S, Zuccatosta L, Bonifazi M, Bolliger CT: Bronchoscopic treatment of emphysema: state of the art. Respiration 2012 84:250-263.

105 Corren J, Manning BE, Thompson SF, Hennessy S, Strom BL: Rhinitis therapy and the prevention of hospital care for asthma: a case-control study. J Allergy Clin Immunol 2004;113:415-419.

106 Compalati E, Ridolo E, Passalacqua G, Braido F, Villa E, Canonica GW: The link between allergic rhinitis and asthma: the united airways disease. Expert Rev Clin Immunol 2010;6:413-423.

107 Usmani OS: Unravelling the small airways: structure-function-treatment relationships in asthma and COPD. Respiration 2012;84:1-3. 